\title{
Fuerza e ironía en Christoph Menke
}

\section{Force and Irony in Christoph Menke}

\author{
Horacio Tarragona \\ Instituto de Investigación en Teorías del Arte y Estética, Facultad de Humanidades, \\ Universidad Nacional de Catamarca. Provincia de Catamarca, Argentina. \\ horaciotarragona@hotmail.com \\ Naím Garnica \\ Instituto de Investigación en Teorías del Arte y Estética, Facultad de Humanidades, \\ Universidad Nacional de Catamarca. conicet. Provincia de Catamarca, Argentina. \\ naim_garnica@hotmail.com
}

\section{Resumen}

Christoph Menke sostiene que el sujeto estético no tiene lugar en la tradición del sujeto hegeliano-heideggeriano. El autor piensa que la subjetividad estética no puede articularse, sin más, con una metafísica del sujeto. El escrito reconstruye tales planteos para pensar más allá del sujeto absoluto recurriendo a dos estrategias: retornar a los conceptos de fuerza de Baumgarten e ironía de Schlegel. Recuperar esas propuestas abre otro modo de comprender la modernidad y la subjetividad.

Palabras clave: sujeto, crítica, modernidad, estética.

\section{Abstract}

Christoph Menke argues that the aesthetic subject has no place in the the tradition of the Hegelian-Heideggerian subject. The author proposes that aesthetic subjectivity can't be articulated in a metaphysic of the subject. Indeed, this article reconstructs such theme to think beyond the absolute subject from two strategies: return to the Baumgarten's force and Schlegel's Irony. Going back to these proposals opens another way to understand modernity and subjectivity.

Keywords: Subject, Criticism, Modernity, Aesthetics. 


\section{Presentación de Christoph Menke}

Christoph Menke es un filósofo alemán que desde 2009 es profesor de filosofía y uno de los representantes de la "tercera generación" de la Escuela de Frankfurt. En español sus publicaciones más importantes son La soberanía del arte (1997), La actualidad de la tragedia (2008) y Estética y negatividad (2011). Son escasos los estudios sobre sus escritos en español. Sin embargo, podemos destacar algunas investigaciones útiles para el abordaje de su obra, en general estudios puntuales relativos a problemas del ámbito de la estética, pero que no abordan exclusivamente su obra, a excepción de la introducción de G. Leyva a los ensayos de Estética y negatividad. A dicho artículo debemos sumar el dede Verónica Galfione, Estética y Política: el debate contemporáneo en torno a las formas de la representación, el cual repasa las tendencias estéticas actuales respecto de los procesos prácticos de estetización política donde Menke entra en diálogo con J. Rebentisch, W. Welsch, R. Bübner y M. Seel, y el estudio introductorio de Esteban Juárez y Verónica Galfione a Modernidad estética y filosofía del arte I. Otro trabajo de referencia es el de Antonio Aguilera, quien contrapone las posiciones de Bürger y Menke en relación a Adorno.

\section{Sujeto, subjetividad y modernidad estética}

En el ámbito filosófico, la oportunidad de marcar la crisis del modelo representacional del sujeto en la modernidad, ha tenido un lugar recurrente. Su cuestionamiento o descentramiento ha sido una constante desde la aparición de los estudios del otro y la emergencia de los supuestos mecanismos opresivos de la cultura occidental. La génesis de ese cuestionamiento sigue, por lo general, dos vías: una vinculada a la ciencia moderna (ciencias sociales, hermenéutica, teorías de género), la otra relacionada al capitalismo (marxismo, teoría política, estudios poscoloniales). Salvando las profundas diferencias, ambas críticas identifican modernidad y subjetividad, lo que supone una reconstrucción epocal desde las ideas de Hegel y Heidegger en vistas a un diagnóstico. En ambos análisis, la modernidad estaría caracterizada por un fundamento que determina a todos los demás: el hombre. El sujeto moderno, en esta significación, involucra supuestos metafísicos que lo promueven como fundamento de todas las determinaciones, substrato de toda representación y signo distintivo de un absoluto que cimienta la época. Sin embargo, la modernidad, sostenemos, no puede ser entendida en este rastreo o, por lo menos, no puede ceñirse a esta comprensión. Siguiendo a Menke podemos reconocer alternativas al modelo metafísico.

Nos interesa aquí disociar subjetividad y modernidad. Más que repetir las críticas sobre la subjetividad moderna pretendemos presentar el modo en que la tradición estética la ha elaborado. Menke muestra dos modos entrelazados de subjetividad estética que permiten releer la modernidad que actualmente, en ocasiones, se ha 
caricaturizado. Recuperar sus planteos no tiene la pretensión redentora de enarbolar las banderas de la modernidad. Antes bien, la intención del presente ensayo es reconstruir la subjetividad estética, a fin de dar cuenta de los efectos que estos desarrollos tienen para desidentificar la reducción de modernidad a subjetividad. Debido a tal reducción, según Menke, la consideración estética ha palidecido. Pese a ello, las reflexiones estéticas alternativas de la subjetividad en la tradición de Adorno y Ritter no pueden ajustarse a la reelaboración del sujeto moderno-metafísico que, por ejemplo, el posestructuralismo lleva a cabo bajo el concepto de autor. Este, todavía, remite a reformulaciones de un sujeto estético sin abogar por su desaparición definitiva ${ }^{1}$, sino por su reinscripción en términos de transgresión y soberanía siguiendo a Nietzsche y Bataille. La subjetividad estética no puede articularse metafísicamente, su reconstrucción nos plantea la necesidad de recurrir a dos estrategias: retornar a los conceptos de fuerza de Baumgarten e ironía de Schlegel (Menke, Estética 91). Es en la estética del siglo xviII donde estarían concentrados los intentos de cuestionar el modelo metafísico del sujeto moderno. A partir de Estética y negatividad, La actualidad de la tragedia y La soberanía del arte de Menke pretendemos reconstruir los planteos a la luz de categorías tales como experiencia, subjetividad y reflexividad estéticas, las cuales remiten a procesos dinámicos de presentación de la obra de arte como producto y producente de fuerzas.

\section{Baumgarten: fuerza y cuerpo}

Detengámonos ahora en Baumgarten para poner en relieve su idea de fuerza y la conexión que tiene con una subjetividad estética crítica según la idea de reflexividad. El racionalismo ilustrado alemán recupera el lema escolástico medieval "nada hay en el intelecto que primero no haya estado en los sentidos", el cual remite a un programa holístico de comprensión y explicación general de la realidad que necesariamente incluye lo sensible y cuyo último estatuto es racional. En el contexto mencionado el lema funciona como una crítica a la taxativa escisión cartesiana entre res cogitans y res extensa. Presuponiendo que toda la realidad es susceptible de racionalización se entiende, por ejemplo, la compulsiva necesidad de Wolff de proyectar ciencias. Su discípulo, Baumgarten asumió el legado de su maestro y explícitamente programó la estética como disciplina ya en 1735. Le dará forma y cierto aspecto sistemático en 1750-58 presuponiendo que el mundo sensible es susceptible de una explicación racional. Esto no es nuevo, pero sí lo es el desplazamiento heurístico y metodológico que

1 Un texto de referencia sobre el tema es de Christa y Peter Bürguer, La desaparición del sujeto. Si bien los autores no elaboran una teoría del sujeto, sino una historia de la subjetividad, su estudio contiene perspectivas contemporáneas que se resumen en dos paradigmas de la subjetividad. El primero corresponde al defendido por Manfred Frank en torno a la defensa de la conservación del concepto de sujeto, y el segundo, al defendido por Lyotard respecto del agotamiento de la subjetividad moderna. 
asume. Si bien la aisthesis en general será tematizada racional y sistemáticamente, el centro desde el cual pasará ahora a ser indagada, no será la res cogitans sino el cuerpo. El mundo sensible retiene en sí elementos impermeables a la conciencia, imposibles de reducir a conceptos del entendimiento, y por ello se los deberá explorar desde miradas y presupuestos diferentes. Este giro heurístico y metodológico de Baumgarten descansa sobre una sensibilidad que opera con sus propias reglas. La irreductibilidad del mundo extenso toma distancia, en cierta medida, del programa racionalista que proyectaba una armonía y continuidad universales. Si bien tal irreductibilidad, puesta ahora en primer plano, transita toda la estética de Baumgarten podemos señalar, como ejemplo elocuente de su desplazamiento metodológico, el hecho de que en su Aesthetica reserva todo un apartado para la taumaturgia. La aisthesis, así enfocada, constituye un primer elemento que nos permitirá contextualizar, ya en su punto de articulación, la subjetividad estética.

El primer aspecto de la aisthesis que sale al paso, su irreductibilidad al modo conceptual de entender el mundo, pone de relieve un peculiar modo estético de mirar, producir, degustar o pensar. Baumgarten retoma de Leibniz un punto que será de capital importancia. Nos referimos al, por todos conocido, no sé qué (nescio quid) del arte. Señala Leibniz: "Conocemos algunas veces, sin lugar a duda, si un poema o un cuadro están bien hechos, porque hay un no sé qué que nos satisface o nos choca" (24). Baumgarten introduce la expresión siempre que habla de la fascinación que algo nos produce: la magia de una mujer, de un poema, de un atardecer. El uso de tal expresión no es casual, de hecho, se relaciona fuertemente con la problemática, por entonces muy común, de lo sublime, tema que se venía desarrollando in extensum desde fines del siglo XVII en el neoclasicismo de Francia y se extiende durante el siglo ilustrado hacia Alemania e Inglaterra. La adivinación y la profecía también se incorporan como objetos propios en el proyecto de la Aesthetica en tanto disciplina. El nescio quid, lo sublime, la adivinación, la expectativa y la taumaturgia en general constituyen, en palabras del mismo Baumgarten, elementos oscuros para la conciencia pero claros para la sensibilidad (Baumgarten, Aesthetica $\$ \$ 614,631,632$ ). De allí la idea de una claridad extensional correlativa a una oscuridad intensional y su correspondiente inversión. El término "intensional” refiere aquí una tensión que permanece en sí misma y representa una fuerte denuncia sobre el riesgo de cierto solipsismo que merodea un sujeto cartesiano que piensa y se piensa. Para Baumgarten, rendir cuentas de lo sensible y de las experiencias taumatúrgicas desde el metafísico sujeto de la conciencia es una contradictio in adjectum. Será preciso situarse en la aisthesis para tematizar y explicar pertinentemente tales fenómenos.

Desde este fundamental distanciamiento crítico, Baumgarten propone alternati-

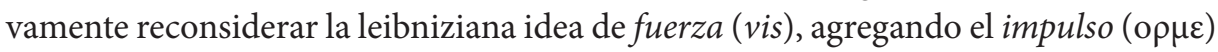
y el impetu (impetus) estéticos los cuales presentan gradaciones ( $\$ \$ 78$ y ss.). La fuerza debe ser ejercitada, es un impulso originario que está inmediata y directamente orientado hacia lo sensible. Revisemos una distinción peculiar de Baumgarten orientada 
a comprender la idea desde su interlocutor. Desde Descartes y hasta el siglo XVIII el sujeto estaba definido, en líneas generales, en términos básicamente metafísicos y cognitivos. El universo denominado extensión quedaba afuera del sujeto y, por lo tanto, sin un fundamento en sí. Baumgarten en su Metaphysica de 1739 se desplaza desde un sujeto sustancial -en tanto substrato abstracto al que se le atribuyen diversos predicados- hacia un sujeto que se define en términos de fuerza. Sostiene que para ciertos sujetos es fácil actuar mientras que para otros ciertos sujetos es difícil. La facilidad o dificultad en el actuar reviste grados según la fuerza. Desde entonces, el sujeto del Baumgarten de la Metaphysica es esencialmente fuerza de la acción en diversos grados:

Necesariamente el actuar es fácil para pocos hombres, para la mayoría es difícil. De aquí que el actuar es fácil para cierto sujeto. Necesariamente el actuar es una pequeña parte de la fuerza de aquel que es eficaz, pero para cierto sujeto es difícil, el actuar es una gran parte de la fuerza en la que la substancia requiere eficacia. Por lo tanto, la facilidad y la dificultad admiten $\operatorname{grados}^{2}$ (\$527).

Menke retoma el problema (Estética 93) y, citando la conocida frase del parágrafo $\$ 505$ de la Metafísica de Baumgarten “anima mea est vis", destaca que el sujeto no es un poseedor y usuario de capacidades, sino que él mismo es una capacidad pura en sí (95). En términos de Baumgarten diríamos que el hombre está facultado con esta fuerza -su acción está referida a y se ejerce en el orden de la extensión-, es natural y la misma que opera en toda la naturaleza en general, su "carácter es también el de las fuerzas vivas en física”3 (Aesthetica \$79). Pero esta fuerza de acción, que varía según los sujetos, es susceptible de ser dirigida y educada mediante ejercicios. El caso paradigmático y heurístico de una educada fuerza de acción sobre la extensión es el arte, producto emergente de una ejercitación como lo es el ingenio, la sutileza, el refinamiento, entre otros. Tales factores se resumen en el pensar, degustar y/o producir en modo bello un objeto. Por lo tanto, el sujeto de Baumgarten no se define en términos metafísicos, trascendentales, cognitivos sino en términos de ejercicio de fuerza de acción sobre la extensión.

Ahora bien, hasta aquí mencionamos un primer distanciamiento crítico (irreductibilidad de la aisthesis) y su consecuente propuesta alternativa (fuerza). Demos un paso más hacia la idea de mímesis que propone Baumgarten. Curiosamente el arte logra retener en sí mismo esa fuerza que le dio origen, es un efecto equivalente en fuerza a la fuerza viva que lo originó. Pero aun más, es una fuerza que cuadruplica la fuerza ordinaria y se mide por el impacto de la obra en el observador, por la cantidad de fuerza que despierta en quien lo observa. Baumgarten sostiene que el ímpetu estético

2 Facile est ad quod actuandum paucae vires necessariae sunt; ad quod maiores requirintur vires, est difficile. Hinc facile certo subiecto est, ad quod actuandum exigua pars virium, quibus illud pollet, necessaria est: certo subiecto dificile, ad quod actuandum magna pars virium, quibus substantia ista pollet requiritur. Ergo facilas et difficultas admittunt gradus. Todas las traducciones son propias.

3 Character etiam virium vivarum in physicis. 
requiere dirigir las facultades hasta el punto en que produzcan "efectos equivalentes a las fuerzas vivas, mayores que las fuerzas ordinarias y las que se consideran alrededor de ellas, a razón de cuatro a uno"4 $(\$ 78)$. Si la fuerza no permaneciese en la obra no podríamos explicar cómo es capaz de reactivar la fuerza del espectador. Esta relación de fuerzas es de orden sensible y despierta las facultades de manera imprevisible (\$80). El caso del éxtasis y el entusiasmo revelan que dicha fuerza es sincrónica en las facultades superiores e inferiores, cuerpo y alma se coactivan (\$81). Ahora estamos observando las facultades superiores desde las inferiores. En esto consiste el giro heurístico y metodológico que antes mencionábamos. Los términos superior e inferior, utilizados por el mismo Baumgarten, no tienen aquí una connotación jerárquica: el autor explícitamente insiste en ello indicando que se trata de cuestiones análogas, paralelas, irreductibles entre sí. El ingenio del artista logra imprimir fuerza en el orden de la extensión, la retiene en sí y será reactivada por quien, al contemplarla, experimente placer, entusiasmo y éxtasis. La idea de transferencia de la fuerza somática hacia la obra se aclara en la idea de mímesis. La imitación no es una relación isomórfica entre las representaciones que proporciona la obra y las representaciones que previamente tiene el sujeto. Muy por el contrario, la imitación está en el mismo orden de las fuerzas. Baumgarten lo señala de este modo:

Sea el GÉnero de pensamiento natural declarado como las fuerzas naturales del alma para pensar objetos de la naturaleza proporcionales a dichas fuerzas, objetos que y de los cuales se debe presuponer que, al ser utilizados o degustados, son susceptibles de conocimiento. O sea, más brevemente, [el género de pensamiento natural] imita las naturalezas de los objetos. Hasta el punto que el género del pensar en modo bello y en modo natural, es necesario para aquellos que se proponen pensar en modo bello y para la naturaleza del alma que se propone pensar en modo bello muchos objetos hasta ahora poco conocidos; al parecer, todos los artificios del conocimiento bello comprenden una única regla: imitar la naturaleza ${ }^{5}$ (\$104).

Entonces, la gradación de fuerza de cierto sujeto se transfiere proporcionalmente, mediante la invención, a la fuerza de cierta obra de arte. La mímesis se da en el orden de la fuerza y estriba en la transferencia del creador a lo por él creado. Una originaria fuerza que tiene efectos cognitivo-simbólicos, siendo la cognición una instancia segunda, mientras que la degustación o utilización es una instancia primera. En estos términos es preciso entender su famosa expresión analogías de la razón [razón análoga] (\$1).

4 atque adeo dent effectus his suis viribus viuis aequales, viribus ordinariis maiores, et ad eas se circiter habentes, uti quadratum ad radicem.

5 NATURALE COGITANDI GENUS si dicatur naturalibus animae cogitaturae viribus, obiectorum, eorumque naturae proportionatum, quibus et quorum in usus vel delectationem cogitatio suscepta praesumenda est, S. brevius has naturas imitatum, adeo necessarium est pulcre cogitaturo naturale cogitandis genus, (\$14) ut minus adhuc cognita animae pulcre cogitaturae, multorumque obiectorum natura, omne venustae cogitationis artificium hac unica regula comprehendi videretur: Naturam imitare. 
La fuerza estética, que se constata en su producción, a diferencia de la fuerza ética o la fuerza que produce objetos útiles o mercancías, tiene una peculiaridad: excepto en los productos estéticos, la fuerza se agota en el producto. Por el contrario, la fuerza estética que se plasma en un producto artístico permanece cuadruplicada en él emancipándose de su productor. En síntesis, la fuerza de cierto sujeto adquiere, una vez transferida, un estatuto independiente objetivo: la fuerza de la obra mimetiza, la fuerza del artista, quien ya no tiene potestad sobre su propia obra. De este modo, la fuerza se emancipa en la obra que al ser contemplada reactiva la fuerza en otro espectador.

Hasta aquí hemos llegado al punto en que la fuerza es autónoma en la obra, pero deseamos poner destacar un cuarto elemento, un giro que efectúa Baumgarten y que consideramos axial en nuestro itinerario. El autor de la Aesthetica señala que los modus dicendi, propios de la retórica clásica y neoclásica, son también modus cogitandi. Permítasenos un breve paréntesis para desarrollar la importancia de esta idea. Como bien sabemos, el modelo clásico de lenguaje establecía una triada secuencial que podríamos esquematizar como pensamiento - lenguaje - mundo. En tal esquema, el pensamiento ocupa un lugar prioritario y el lenguaje constituye un simple medio representativo que otorga acceso al mundo. Frente a este modelo clásico, podemos mencionar lo que suele llamarse el paradigma romántico del lenguaje (Hamann). En este segundo modelo, no hablamos porque pensamos sino que pensamos porque hablamos, el esquema sería: lenguaje - pensamiento - mundo. En ambos modelos encontramos una subordinación: en el primer caso, del lenguaje al pensamiento y, en el segundo caso, del pensamiento al lenguaje. Una posibilidad alternativa nos ofrece Baumgarten, en la que la subordinación se da según el caso y no puede establecerse de modo absoluto a priori. Es posible que el modo de pensar determine el modo de hablar, pero en el caso del arte, el modo de hablar determina un singular modo de pensar: el modus dicendi articula el pulcre modus cogitandi, esencial en la estética. Por lo tanto, podemos ahora asociar la idea de fuerza autónoma a la idea de un modo de pensar bello subordinado al modo de hablar. La fuerza autónoma de la obra suscita sincrónicamente un modo de pensar pero sin despegarse de la misma experiencia. En este sentido, la poesía es autónoma, su fuerza propia coloca en primer plano el carácter verbal del cual se deriva su carácter cognitivo o judicativo. A ese modo bello de pensar, que se da por y en la fuerza autónoma de la obra lo llamaremos reflexividad. Mencionemos provisoriamente que no se trata de una reflexividad mathemica, sino askésica. Volveremos sobre este punto más adelante.

Respecto a esto, Menke observa que para Cassirer la historia alemana del siglo XVIII presenta una figura de reflexión ${ }^{6}$. Esta figura que, en palabras de Schlegel, se

6 Ernst Cassirer en Filosofía de la Ilustración explica en relación a los desarrollos de la filosofía alemana y francesa del siglo xviII la figura de Baumgarten y de qué modo se siguen los caminos abiertos por Leibniz en los órdenes del saber de la naturaleza: "El discípulo más importante de Wolff en Alemania, Baumgarten, manifiesta también su independencia espiritual y su originalidad en este punto. Baumgarten encuentra en su metafísica y, en especial, en el esbozo de su estética, el camino que le conduce de nuevo a ciertas ideas fundamentales de Leibniz que hasta 
denominaría trascendental, se entendería "como la disolución de la obra en acción, del ser en devenir, del producto en lo que produce" (Menke 94-5). A juicio de Cassirer, esto equivale a una reducción al sujeto, la disolución reflexiva de la forma en una capacidad, entendida esta como fundamentación de la forma en la libertad. Esto supone que la autonomía del sujeto prepara su comprensión estética como autor de sus actividades. El paso del sujeto como fundamento de la época al sujeto estético es un paso hacia la comprensión kantiana e idealista. Pero debemos advertir que la terminología de Cassirer da lugar para que se pueda atribuir la capacidad, la acción y el devenir a un sujeto productor que es dueño y soberano de dichas capacidades. Tal atribución parece cuestionable si consideramos al sujeto como una fuerza, y no como una máquina de control de capacidades y funciones. Esto hace evidente la dificultad de inscribir a Baumgarten en la tradición de una filosofía del sujeto -como por ejemplo lo hacen Hegel y Heidegger-, en particular, si disociamos sujeto y producción. Cassirer, según Menke, equivoca el camino de su apropiación de la filosofía del sujeto al creer que esta desemboca inevitablemente en el idealismo ${ }^{7}$.

A partir de la reflexividad a la que habíamos arribado y que derivamos de la idea de fuerza, Baumgarten rompe con la restricción de identificar sujeto con modernidad y metafísica. La potencia del sujeto estético ofrece un impulso que abre caminos productivos para repensar la subjetividad y la modernidad. A fortiori nos interesa, a continuación, puntualizar otro camino al ya recorrido por Baumgarten.

\section{Schlegel: ironía y poesía trascendental}

A partir del modelo de la poesía trascendental de Schlegel, Menke retoma la cuestión de la subjetividad estética. Su recuperación está centrada en tres elementos: la obra de arte, el concepto de crítica y el de ironía. Como Kant, Schlegel también habla de

ese momento permanecían ocultas. El desarrollo de la estética y de la filosofía de la historia alemanas lleva ahora una concepción original y profunda del problema de la individualidad, tal como aparece señalado en su origen en la doctrina de las mónadas y en el sistema de la armonía preestablecida de Leibniz" (51-2).

7 Cassirer establece una continuidad entre las teorías de la ciencia del siglo XviI (Descartes y Leibniz), las del siglo XVIII (Wolff y Baumgarten), y el idealismo alemán (38), aclarando que paulatinamente comenzó a ponerse más el acento en lo particular que en lo universal, más en los fenómenos que en los principios. Cassirer supone un decurso convergente de la estética que poco a poco se va abriendo camino hasta llegar a su consumación. El autor sostiene que en el siglo XviII se da la fundación de la estética sistemática, "Pero antes de que se lograra esta síntesis y que cobrara en las obras de Kant su forma firme, el pensamiento filosófico tuvo que recorrer una serie de etapas previas" (305, énfasis nuestro). Los diversos pensadores son considerados, como "etapas" del teleológico desarrollo de una idea, en este caso, la "estética", la cual gracias a un juego dialéctico se va "puliendo" hasta adquirir un "lustre" sistemático en Lessing y, finalmente, en Kant. El mito indicado pone de relieve supuestas continuidades en virtud de un ideal de claridad y objetividad de principios (316). Este paralelismo traza una línea coherente hasta llegar a Baumgarten que, según Cassirer "es uno de los primeros pensadores que ha superado la dualidad de sensualismo y racionalismo y ha iniciado una nueva síntesis productiva de razón y sensibilidad" (2005: 387, énfasis nuestro). Creemos que, tal vez, leer a Baumgarten en clave de decursos dialécticos y superaciones sintéticas sea apresurado o incluso anacrónico. La relación entre sensación e intelección en Baumgarten señala esferas irreductibles entre sí que impiden una síntesis final. De hecho, sus Consideraciones sobre el poema tienen muy poco de sistemático, y la misma Aesthetica si bien tiene un aspecto más ordenado, muy lejos está de constituir un sistema deductivo ordenado de cuestiones. 
reflexión "crítica", pero en un sentido radicalmente distinto ${ }^{8}$. Para el autor romántico la crítica es una determinación interna de la obra, inmanente a ella9. Además, la crítica es una condición de la poesía: su carácter trascendental representa un aspecto reflexivo en tanto es "poesía de la poesía". La reflexión exhibe al producente con el producto, pero la causa de ese producente no es el sujeto. La obra, al igual que la reflexión, "es una viva individualidad que se produce, evalúa y presenta a sí misma" (Menke, Estética 108). En el fragmento n 238 de Athenäum, sobre el que Menke hace especial hincapié, dice Schlegel:

Hay una poesía cuyo principio y fin es la relación de lo ideal y lo real, por lo cual esta poesía debería llamarse poesía trascendental por analogía al lenguaje filosófico artificial. Como sátira comienza con la absoluta diferencia de lo ideal y lo real, flota como una elegía en el medio y termina como un idilio con la absoluta identidad de ambos. Así como se le daría poco valor a una filosofía trascendental que no fuese crítica, que no presentara lo producente con el producto y que en cierto modo contuviera una característica del pensamiento trascendental, así esta poesía debería reunir los materiales trascendentales no poco frecuentes en los poetas modernos y los ejercicios de una teoría poética de la facultad de poetizar con la reflexión artística y la auto-reflexión (...). Esta poesía debería presentarse a sí misma en cada una de sus presentaciones y ser por doquier a la vez poesía de la poesía (170-1).

Por un lado, la autorreflexión estética no es el acto de un sujeto y, por otro, el desarrollo de lo reflexivo, lo reflexivamente explorado, no es una facultad del sujeto. Menke observa que Schlegel promueve una teoría de la presentación, en la cual la reflexión en tanto producto "de una forma de presentación de un nivel más elevado, es capaz de presentar algo y junto con ello lo presentante" (Menke 109) ${ }^{10}$. Tanto en los ensayos de Estética y Negatividad como en Laactualidad de la tragedia Menke intenta advertir que el pensamiento de Schlegel se encuentra atravesado por la autorreflexión, la copresentación y corepresentación. La subjetividad estética derivada de la concepción schlegeliana es para Menke una presentación de un producto que exhibe sus condiciones de presentación a la vez que se presenta. La subjetividad, en ese caso, tiene la posibilidad de volverse reflexiva sobre sí y, por tanto, crítica de sus propios presupuestos.

8 Contra nuestra hipótesis pueden verse los estudios detallados de la herencia kantiana e idealista en el prólogo de Rodolphe Gasché a la edición inglesa de los fragmentos de Schlegel, titulado "Foreword. Ideality in Fragmentation". Y también en los estudios de Beiser German Idealism: The Struggle Against Subjectivism, 1781-1801 y The Romantic Imperative: The Concept of Early German Romanticism.

9 Para una profundización de la crítica como inmanente a la obra puede verse El concepto de crítica de arte en el romanticismo alemán de Walter Benjamin.

10 En la misma dirección parece conducirse la reflexión sobre los modelos de arte que el joven romántico postula del arte romántico en el Fragmento Athenäum n 247: "El poema profético de Dante es el único sistema de la poesía trascendental, siempre el más elevado de su especie. La universalidad de Shakespeare es como el eje central del arte romántico. La poesía puramente poética de Goethe es la poesía más completa de la poesía. Esto es el triple acorde perfecto de la poesía moderna" (Schlegel, "Fragmentos" 172-3). 
Menke enfatiza respecto de la forma en que Schlegel, en su período de juventud, entiende lo producente de aquellas fuerzas copresentadas en la poesía trascendental. A partir del concepto de ironía, Schlegel impugna una tradición de pensamiento que se extiende desde Leibniz hasta Kant. Su planteo, alineado en las ideas de Baumgarten, reformula la consideración sobre las fuerzas que poseen una orientación teleológica como efecto de facultades constitutivas del sujeto. La ironía, al definir el modelo reflexivo de la poesía trascendental, supone un devenir interminable que flota oscilando entre la autocreación y la autodestrucción. En tanto reflexividad crítica, la ironía es simultáneamente destructiva y constructiva, una acción productora que retiene un componente destructor de sí. Por eso la "crítica en cuanto reflexión teórica sobre la creación y los productos creados (lo producente y lo producido) constituye desde sus orígenes uno de los elementos más característicos del trabajo del romanticismo" (Sánchez Meca 239). La obra de arte se concibe ligada a su momento creador, sin embargo, dicha creación se encierra de forma inmanente, esto es, la autoreflexión y teorización reflexiva de su actuar ${ }^{11}$. La crítica, de ese modo, se caracterizaría por un tipo de reflexividad irónica ambivalente y pendular entre su producción y reflexión destructiva de sí.

En este punto, el análisis de Menke podría ponerse en consonancia con las consideraciones sobre la crítica de Jean-Luc Nancy y Philippe Lacoue-Labarthe para quienes la crítica es una ciencia del criterio. La tarea de la crítica se define como formación del carácter, es decir, presentación de capacidades para hacer obras. Los pensadores franceses indican:

La filosofía no puede entonces ejecutarse a través de la crítica sin antes haber sido [...] caracterizada por esa misma crítica [...] Sea cual sea la conclusión es la misma: hay que poetizar la filosofía y le corresponde hacerlo a la crítica [...] la filosofía -no olvidemos que esto quiere decir aquí la ciencia misma del ideal- no está formada. La crítica debe formar su carácter [...] La característica constituye la esencia de la crítica porque quiere ser la ciencia del criterio $[\ldots]$ El kriterion da el idioma, la propiedad, y lo distingue del phantasma, de la vana ilusión. Conviertan la representación en presentación, hagan del fantasma un idioma y tendrán la criteriología del romanticismo [...]. Una ciencia, entonces, del carácter como phatos -dicho de otro modo, si Friedrich consentía en ser coherente con el recurso a la lengua griega, una estética de la sensibilidad profunda. Es decir, aun una ciencia de esas pasiones sofrenadas por Platón por

11 En Modernidad y Romanticismo Diego Sánchez Meca, a diferencia de Menke, deja entrever que los románticos elaboran una subjetividad creadora que le otorga el poder al sujeto como productor de la obra. A su juicio, la ironía singulariza su tensión: libertad y autonomía son correlato de la dinámica de la autolimitación y autoformación de la obra de la ironía. Meca señala, por tanto, una especie de catálogo de propiedades y obligaciones del sujeto romántico: "el individuo romántico debe trascender todas las formas en las que expresa concretamente su yo una y otra vez. [...] debe conocer los límites de cada una de las identidades que ha alcanzado, comprender su relatividad y liberarse así, autolimitándose de este modo de esa otra autolimitación que representa el hecho de verse reducido, incluido, relegado a una única versión de sí mismo" (247, cursiva del texto original). 
la razón filosófica y agitando, desde la catarsis de Aristóteles (y hasta Schlegel a través de la historia de lo patético en los siglos XVII y XVII), lo más claro y lo más oscuro del deseo de la literatura y dándole para bien y para mal la esencia de su género (Nancy y Lacoue-Labarthe 479-81).

Dicho proceso es la aleación ideal entre creatividad y crítica. La obra es expresión entre el sujeto productor y su obra. De ello Menke desprende una reflexividad estética sustraída de la metafísica del sujeto y la modernidad. En la ironía, la reflexión no puede sustancializarse debido al movimiento flotante que posee. Del mismo modo, analiza las consideraciones de Schlegel sobre la tragedia. Si la ironía es la posibilidad de la subjetividad de presentar al sujeto y, simultáneamente, impugnarlo para volver al proceso de postulación, la tragedia evidenciaría los mismos rasgos. Valiéndose de la concepción de poesía trascendental, Menke sostiene que la tragedia para Schlegel adquiere una constitución trascendental. Nuevamente, haciéndose eco del Fragmento de Athenäum $\mathrm{n}^{\circ} 238$, indica que, en su presentación como producto, la tragedia contiene siempre las formas de su producción. Recuperamos una cita de La actualidad de la tragedia con el fin remarcar la insistencia de Menke sobre esta dimensión del pensamiento de Schlegel:

\begin{abstract}
en la tragedia, su autoreflejo en el drama no se da simplemente de modo que se encuentran contenidos en ella los materiales a partir de los cuales es posible desarrollar una teoría de la tragedia (aunque esto también sea cierto), sino de modo que los personajes de la tragedia se comportan en relación consigo mismos y con los demás siguiendo patrones estructurales que determinan la forma de la tragedia. Ésta es la manera en la que la tragedia es autoreflexiva: es una representación de actores que simultáneamente es una co-representación de lo que representa; las relaciones entre los personajes que actúan exponen a la vez las relaciones entre personaje, texto y autor. El hecho de que la autorreflexión sea constitutiva de la tragedia no sólo significa que no existe ninguna tragedia en la que no se dé también corepresentación de su forma, sino que la tragedia sólo se forma mediante esta corepresentación de su forma; es decir, que en la tragedia lo trágico del contenido representado tiene su base en la corepresentación de su forma (Menke, La actualidad 77).
\end{abstract}

\title{
Ironía, experiencia y reflexividad
}

El modelo de reflexividad de la ironía, entonces, conjetura una acción desestructurantedeconstructiva de autocrítica. Todo logro de las facultades del conocimiento se ve cuestionado por la destrucción que perpetra la ironía la cual no es una facultad del sujeto, sino la constitución de la reflexividad misma. Para Menke la ironía representa un juego donde la determinación de la reflexión no puede estar dada por el sujeto sin 
que este se exponga a su límite ${ }^{12}$. En ese caso, la ironía no es la égida que le permite al sujeto poner en devenir la obra. La poesía, el sujeto poético produce-pone, y la ironía relativiza esas postulaciones empujándolas a una destrucción. Su proceso crítico deconstructivo radica en un devenir que impediría fijar formas y desembocaría en una tensión entre poesía y totalidad. Esta última nunca sería actual sino una suerte de ausencia-muerte a lá Blanchot. El juego de la ironía no dispone de las condiciones de posibilidad para pensar en un sujeto soberano y substancial de las presentaciones reflexivas, sino de actos reflexivos en devenir.

El desplazamiento desde el sujeto determinante de la reflexión hacia una subjetividad atravesada por reflexividades involucra el peso de la libertad, en tanto el sujeto liberado también envuelve una necesidad. La ironía presenta antagonismos entre lo incondicionado y lo condicionado, entre la imposibilidad y la necesidad de una comunicación. Schlegel identifica lo incondicionado con lo producente, aquello que no es capaz de una comunicación completa. La poesía, en tal caso, sería productora de sí misma y no condicionada por otros factores. Esto la tornaría incomunicable, dado que lo incondicionado producente no se consuma en un producto condicionado. Al contrario, cualquier forma condicionada o finita que se haya generado sería disuelta. Menke rescata, en ese recorrido y en consonancia con Baumgarten, que la ironía mantiene "la lógica anti-teleológica de la fuerza y de su acción" (Estética 110). La fuerza de presentación de la poesía no es la causa de un motor propulsor que queda encubierto como sustancia fundamental y originaria. La poesía para Schlegel puede ser trascendental, esto es, la "co-presentación reflexiva de su fuerza productora" (110). El proceso de entender así la fuerza y la reflexión no es un camino hacia un fundamento seguro, "experimentar algo en cuanto fuerzas significa experimentarlas en la perspectiva de la ironía: como momento transitorio en el cambio entre creación y destrucción, establecimiento y disolución" (110). En el Fragmento de Athenäum n ${ }^{\circ}$ 116 la poesía romántica tiene la posibilidad de:

flotar en el medio entre lo presentado y lo presentante, libre de todo interés real e ideal, sobre las alas de la reflexión poética, puede potenciar siempre esta reflexión y multiplicarla en una serie infinita de espejos [...] El género poético romántico está aún en devenir. En efecto, su auténtica esencia es que sólo puede devenir eternamente, nunca puede ser completamente (147-8).

12 Según el romanticismo, un modelo ejemplar de la reflexividad irónica sería el Wilhelm Meister de Goethe. Esta novela exige una reflexión crítico-irónica del autor que no puede manifestar un carácter definitivo y concluso de la obra sino fragmentario, provisional y alusivo. Esto conjura la creación poética y la reflexión teórica ya que la novela incluye y, a la vez, resuelve, teoría y crítica. En ese caso, en la obra coexisten el productor y el crítico. La doble condición de la subjetividad productora desencadena un proceso de potenciación sin fin como proceso de reflexividad productiva. Este es el modelo de imposibilidad de la comprensión que Paul de Man destaca de Lucinde de Schlegel, pues lleva abiertamente a la incomprensión. La forma paradojal en la que se presenta la ironía manifiesta lo condicionado del poeta, pero también su libertad incondicionada. El sujeto, al igual que la novela, posee una reflexividad que le permite autointerpretarse y autocriticarse para unificar esos momentos. La ironía romántica conserva una base que consiste en el ejercicio crítico entendido como un sacrificio de lo finito en lo infinito. 
Según Menke, esto ubicaría a Schlegel en el comienzo de una tradición que se desmarca de la clásica teoría del sujeto tan cuestionada por el posmodernismo ${ }^{13}$.

La subjetividad irónica refiere una reflexión estética en tanto proceso que produce y disuelve, que no es producto de un sujeto. Si bien dicho proceso desveló al posestructuralismo, esta corriente mantuvo una terminología metafísica sobre la subjetividad (136-7). Menke invierte la tradición moderna señalando que la subjetividad es un modo de determinación de la reflexividad estética y no a la inversa. Subraya que las obras de arte son estructuras de presentación que hacen resaltar la actividad de lo producente y con ello las fuerzas del presentar. Este modelo de reflexividad artística es deudor de Schlegel y podría denominarse crítica trascendental. La crítica hace aparecer lo dado como producido o lo dado en su producir, es decir, expone a lo producente en el producto, crea y exhibe en orden a la destrucción. La poesía trascendental presenta el producto y lo producente simultáneamente. El potencial reflexivo de copresentación es la bella autorreflexión. La obra de arte es reflexiva en tanto se tematiza a sí. Este, precisamente, es el sentido asignado por Paul de Man a la alegoría y a la crítica. Alegorías son aquellas lecturas que las mismas obras hacen de sí mismas, su tragedia reside en que descubren que están hechas de palabras y su lenguaje es enjuiciado cuando se exhibe. Por su parte, el proceso de ironización, al que alude Schlegel y es empleado por Paul de Man, permite advertir que la reflexión estética tiene una doble mirada coexistente: es objeto y crítica de $s^{14}{ }^{14}$. De ese modo, la alegoría afirmaría, a los efectos de contrarrestar el símbolo como totalidad, su distancia respecto de su origen, estableciendo el vacío de su diferencia.

La reflexividad irónica impide una identificación ilusoria entre el yo y un supuesto no-yo. Esa reflexividad se reconoce en el dolor que impulsa la ausencia de fundamento e identificación totalizante donde encuentra su voz la literatura romántica. La explicación demaniana de esta reflexividad sería la siguiente: "Lo que describe sólo puede llamarse "alegoría” es una narrativa, una historia la que él [Fichte] cuenta, una difícil y emocionante historia [...] Nos hallamos ante una alegoría, ante la narrativa de la interacción entre el tropo por un lado y la acción como postulamiento por otro" (De Man 249).

La ironía convive con la alegoría a medida que acerca las temporalidades, es decir, lo hace a través de la coincidencia y la identificación, sino mediante la diferencia y la disociación. La brecha disociativa destraba el fundamento totalizante. Su proceso es esa continua sustitución de posesiones que el tropo genera. Por eso, la subjetividad estética es aquí una continua tensión entre el supuesto control del artista sobre su creatividad y el mundo de los objetos que produce. El propio Schlegel alude a este proceso en el Fragmento ${ }^{\circ} 37$ de Lyceum cuando indica:

13 Pueden consultarse los estudios de Gianni Vattimo Más allá del sujeto y El fin de la modernidad.

$14 \mathrm{Al}$ respecto puede consultarse la trilogía de obras de Paul de Man, de fuerte influencia romántica, en particular la primera y la última, compuesta por los ensayos agrupados en: Alegorías de la lectura, La ideología estética y La retórica del romanticismo. 


\begin{abstract}
De este modo, no sabe apreciar el valor y la dignidad de la autolimitación que es, sin embargo, para el artista como para el ser humano en general, lo primero y lo último, lo más necesario y lo más elevado. Lo más necesario, porque dondequiera que no se limita uno a sí mismo se ve uno limitado por el mundo, con lo que se convierte en un esclavo. Lo más elevado, porque uno sólo se puede limitar a sí mismo en los puntos y en los aspectos en los que posee fuerza infinita, creación y destrucción de sí mismo. Incluso una conversación amistosa que no se puede interrumpir libremente en cualquier momento por un arbitrio incondicionado tiene algo de iliberal. Pero un escritor que puramente quiere y puede explicarse, que no se reserva nada para sí y gusta decir todo lo que sabe, es muy de lamentar. Sólo hay que guardarse de tres errores. Lo que parece y ha de parecer arbitrio incondicionado y, por consiguiente, irracional o suprarracional debe ser, sin embargo, en el fondo, de nuevo absolutamente necesario y racional; en caso contrario, la disposición se torna capricho, surge la iliberalidad y la autolimitación se convierte en autodestrucción. En segundo lugar, no hay que tener demasiadas prisas con la autolimitación y hay que dejar primero espacio a la creación de sí mismo, a la creatividad y al entusiasmo, hasta que se hayan culminado. En tercer lugar, no se debe exagerar la autolimitación ${ }^{15}$ (52).
\end{abstract}

La obra queda así fragmentada y jamás alcanza una definición o acabamiento, es víctima de su propia finitud. El negar la conclusión desfigura la identidad última del fragmento y lo potencia más allá de sí: “Todo fragmento, todo libro que no se contradice a sí mismo es incompleto” (Schlegel 1999 52).

Algunos análisis ven en el modelo de reflexión irónica de Schlegel una dependencia estructural de Fichte. La ironía como modelo de praxis y conocimiento irresoluble ha sido considerada inconducente. Desde cierto perspectivismo y relativismo, se suele cuestionar la sustitución de lo universal de los sistemas filosóficos que la ironía destruye por la necesidad de lo no-obligatorio. Estos planteos anti irónicos de raigambre hegeliana suponen que las extralimitaciones del artista como deconstructor de sus objetos arrastran por necesidad al nihilismo y la imposibilidad ${ }^{16}$. Menke evita incurrir en la reducción fichteana de la ironía al ligarla con la tradición de Baumgarten. Este patrón alternativo puede rastrearse en el Fragmento del Lyceum $n^{\circ} 108$ :

15 Tanto Diego Sánchez Meca como Domingo Hernández Sánchez destacan de ese pasaje el movimiento dialéctico que piensa la crítica por medio de la ironía como un efecto del artista sobre su propia obra. Primero, el artista crea desde adentro hacia afuera, pero en un segundo momento, en su regreso, no se reconcilia en una totalidad con la obra; en cambio, lleva a cabo una autocrítica irónica que le permite autolimitarse accediendo a una objetividad posterior que es producto de la ruina en la que la obra queda luego de la ironía. Estos estudios afirman que en la ironía se encuentra cifrada, en categorías estéticas, la reflexión y autoreflexión fichteana mediante la cual el sujeto se convierte en objeto para sí mismo. La reflexión estética queda así subordinada a una dialéctica infinita del yo.

16 Tales críticas a la ironía pueden consultarse en Klaus Vieweg "Ironía romántica como skepsis estética”. También pueden consultarse las equivocadas críticas a la ironía romántica en Die kritik der Romantik de Bohrer. 


\begin{abstract}
La ironía socrática es la única simulación enteramente involuntaria y, sin embargo, enteramente reflexiva. Es tan imposible fingirla como develarla. Para quien no la posee permanece como un enigma incluso tras la más abierta declaración [...] En ella todo ha de ser burla y seriedad, todo lealmente sincero y todo profundamente disimulado. Nace de la unión del sentido del buen vivir y el espíritu científico, del encuentro entre la perfecta filosofía natural y la perfecta filosofía técnica. Contiene y provoca un sentimiento del irresoluble conflicto entre lo incondicionado y lo condicionado, de la imposibilidad y necesidad de una plena comunicación. Es la más libre de todas las licencias, pues a través de ella se sitúa uno más allá de sí mismo; pero es también la más reglada, pues es incondicionalmente necesaria" (Schlegel, Poesía y filosofía 62-3).
\end{abstract}

La ironía es la irresoluble contraposición entre el mundo condicionado de la naturaleza y el mundo incondicionado de la libertad. Por eso es necesaria la mediación libertad-necesidad, sin embargo, esta es paradójicamente inalcanzable. El Fragmento $\mathrm{n}^{\circ} 48$ del Lyceum Schlegel sugiere: "La ironía es la forma de lo paradójico. Paradójico es todo lo que es a la vez bueno y grande" (54). Tal vez por esto Harold Bloom entiende que Schlegel es el genuino precursor de Paul de Man: ambos piensan que la disolución conduce a la imposibilidad, no obstante, tal disolución no impide la construcción de una reflexividad ${ }^{17}$. La única alternativa que Bloom identifica en esa dirección es "el triunfo de la ironía romántica en una forma purificada mediante la alegoría de la lectura que formuló Paul de Man” (26). Sin embargo, esa alternativa destructiva y reconstructiva, asume un riesgo que ya Schlegel había notado: "La ironía de ironías es el hecho de que uno se cansa de ello si se le ofrece en todas partes todo el tiempo" (26).

\title{
Subjetividad y reflexividad
}

Reemplazar subjetividad por reflexividad no supone para Menke eliminar la primera. La reflexividad estética no es un producto autónomo del sujeto, una decisión arbitraria del artista. En el devenir creador de estructuras artísticas, la actualización no acontece por un sujeto sino a través de él. Según Menke esto puede verse en la teoría de la presentación de la poesía trascendental de Schlegel. Esa presentación se da en una relación de reflexividad que se muestra en la ejecución del reflexionar. Entonces, el lugar del sujeto, ahora sujeto de reflexiones, es la reproducción de

17 Bloom reconoce las dificultades de la lectura, sin coincidir plenamente con Paul de Man sobre la imposibilidad de la lectura; pero, precisamente a identificar tales dificultades es a lo ha tratado de referir con el tropo crítico de "deslectura" o "desacato". Esto significa que la ironía puede desembocar en un cansancio destructivo, equivalente poético del concepto freudiano de defensa. Justamente, lo que hace la deconstrucción demaniana es disolver y transformar en ironía el corazón mismo del ser poético, es decir, su narcicismo. 
procesos de presentaciones, en consecuencia, la reflexividad no es un producto del sujeto, sino el resultado de modos de presentación como copresentación del presentante en lo presentado ${ }^{18}$.

Sin embargo, la reflexividad no puede entenderse a modo de una mera propiedad objetiva de la presentación. Los actos de reflexión-presentación, no existen sin que los actos de reflexión los reproduzcan. Reformular la subjetividad como ejecución necesaria de la reflexividad nos permite criticar aquellas posturas que piensan el arte en relación al contenido como algo objetivo ${ }^{19}$. Menke señala que "el sujeto no puede reflexionar sin repetir, tampoco puede repetir ningún proceso reflexivo sin reflexionar él mismo. Por tanto, una teoría de la modernidad en cuanto teoría de su reflexividad siempre seguirá siendo también una teoría de la subjetividad" (Menke, Estética 114). La autorreflexión estética de la obra se presenta si es experimentada como producente de sí misma. La reflexividad estética de Schlegel supone pensar dentro de la teoría de la subjetividad una reflexión que, no ejecutada por un sujeto, es llevada a cabo en la presentación que se produce a sí. La obra de arte consiste en el uso comunicativo de la relación producto-producente en tanto constelación que genera significados. Esa reflexividad estética solo le corresponde a la obra como forma de praxis que apunta a presentar de otra manera lo que se hace habitualmente. Por lo tanto, constituiría una transformación de los modos de presentación de la experiencia estética.

18 Estos planteos se encuentran en la interpretación francesa del romanticismo. El texto de Nancy y Lacoue-Labarthe sobre el romanticismo y su escritura fragmentaria marca esa doble actividad a la que se ve sometida la ironía. A propósito, reproducimos el pasaje de manera extensa donde se explica con detalle en relación al concepto de fragmento: "Hasta cierto punto es lícito aplicar a todos los fragmentos la fórmula empleada por F. Schlegel para las Ideas: cada una de ellas "señala hacia dentro" (Id. 155). Sin embargo, ni uno ni otro de los conceptos que aquí empleamos pertenecen al espacio de los Fragmentos propiamente dichos, y hay que decir que no se trata en ellos exactamente de un "señalar" ni de un "centro". Conforme a lo que habría que arriesgarse a llamar más bien la "lógica del erizo", la totalidad fragmentaria no puede estar situada en ningún punto: se encuentra simultáneamente en el todo y en cada parte [...] La totalidad es el fragmento mismo en su individualidad acabada. Es igualmente la totalidad plural de los fragmentos, que no compone un todo (de un modo, digamos, matemático), pero que replica el todo, lo fragmentario mismo, en cada fragmento. Que la totalidad esté presente como tal en cada parte, y que el todo no sea la suma sino la co-presencia de las partes en tanto co-presencia a fin de cuentas del todo ante sí mismo (puesto que el todo es también lo suelto, la clausura de la parte), tal es la necesidad fundamental que deriva de la individualidad del fragmento: lo totalmente-suelto es el individuo, y "de cada individuo hay una infinidad de definiciones reales" (Ath. 82). Los fragmentos son al fragmento sus definiciones, y esto es lo que inviste su totalidad como pluralidad, y su acabamiento como inacabamiento de su infinidad" (88-9, énfasis nuestro).

19 En consonancia con estos análisis del sujeto parecen estar las teorías de la subjetividad elaboradas por el posestructuralismo. Un ejemplo paradigmático de esta concepción del sujeto es la desarrollada por Judith Butler en su Teoría de la Performatividad. El sujeto es un sujeto de actos que se reproduce por fuerza performativa de las leyes discursivas, y no por decisión unánime de su voluntad y ejercicio de libertad. Desidentificar al sujeto político constituye la tarea y el proyecto de Butler ante el inminente peligro de la re ontologización del sujeto liberal, quien se escuda en el discurso de la tolerancia ante lo diferente y el constructivismo. Ese peligro forma parte de aquellas posturas que suponen una identidad como clausurada y totalizante en un sujeto que, a modo de centro de operaciones, controla la construcción de su identidad y sus formas de agenciamiento. El posicionamiento de Butler tiene como propósito impugnar no sólo la ontologización de la construcción, sino también evitar que se entendiese como "segunda naturaleza". Omitiendo la carga semántica analítica del término "performatividad", mutatis mutandis, la idea de performance aporta un elemento para la comprensión de la reflexividad en cuanto sugiere una acción que sin trasfondo ontológico involucra dos elementos: la reflexión del artista (o espectador) y la reflexión de la obra misma. Según esto, fuerza e ironía performan un acto reflexivo simultáneo entre artista y arte. 
El proceder alternativo de la reflexión estética es un modo de ejecuciones de presentaciones y, al mismo tiempo, determina su uso no estético, el hacia afuera. Para Menke el arte "es en el lugar y en el momento donde y cuando se practica una relación reflexiva con el uso habitual de presentaciones como producto utilizable y entendible" (138). La práctica artística ahora puede entenderse como subversiva o transgresora, si por intermedio de su reflexividad suspende la praxis habitual del uso comunicativo de presentaciones, dado que pone de relieve aquello olvidado o presupuesto. En Soberanía del arte, Menke indica:

\begin{abstract}
Es preciso, por lo tanto, explicar el concepto de autonomía del arte de manera que dé cuenta plenamente de su independencia frente a las otras reglas del discurso, y que sea igualmente compatible con el concepto de soberanía. Es necesario, al mismo tiempo, explicar esta noción de manera que se afirme su potencial crítico frente al predominio de la razón, sin que signifique menoscabo heteronómico del principio de autonomía. Solamente si ambas tareas pueden ser llevadas a término simultáneamente, existirá la posibilidad de defender la determinación bipolar de la experiencia estética contra los que, desde frentes diferentes, no quieren ver en ello más que una nostálgica supervivencia (16).
\end{abstract}

La consideración de la subjetividad estética en Menke afecta al establecimiento de la teoría de la modernidad reducida a la época del sujeto sustancial. El camino delineado por la tradición estética no parece asumir los compromisos epistemológicos y metodológicos del discurso de la modernidad que presupone una teoría del sujeto como fundamento. No es la subjetividad el rasgo definitorio de la modernidad sino la reflexividad. Este tipo de reflexión moderna se retrotrae a aquello por lo cual las formas del mundo, su presentación, han sido formadas (performances). Esa generación de formas puede investigarse de distinto modo, pero si se sigue la línea que hemos rastreado aquí, la ironía y la fuerza adquieren un valor fundamental. La propuesta de la estética de Menke, según lo indicado, coloca a la reflexividad estética como modo de la experiencia moderna: "esta exploración reflexiva de la generación de formas es característica de la experiencia de la ironía, la cual ve proceder las formas a partir de fuerzas, de tal manera que ellas al mismo tiempo se disuelven en la acción de éstas, en su juego" (Estética 112).

\title{
Conclusión
}

La crítica a la reducción del sujeto moderno al sujeto de la conciencia nos ha mostrado sus límites a la luz de la idea de un sujeto estético y una experiencia cuya reflexividad hace pie en las ideas de fuerza e ironía. Estos dos conceptos articulan dicotómicamente estética y crítica. Por el lado de la estética, la experiencia concreta de placer y deseo que, por ejemplo, nos proporciona el arte siempre tiene un carácter crítico de todo 
aquello que produce o puede producir el entendimiento y la razón. Por el lado de la crítica, esta debe hacer énfasis en una experiencia concreta, no puede reducirse a una serie de conceptos desarraigados de lo experiencial y vivencial. La estética es crítica de por sí, y la crítica no es tal si no tiene un arraigo estético (Eagleton). Menke se refiere a ello al elaborar una crítica de la crítica: una filosofía que constitutivamente es crítica por el hecho de ser estética. La fuerza y la ironía son conceptos críticos en tanto devienen estéticos: su radical negación a una identificación definitiva es la escena propia de una reflexividad estética. Tanto para la ironía como para la fuerza, la posibilidad crítica reside en un movimiento lúdico que elude por su reflexividad la normatividad del pensamiento.

Pero demos un paso más retomando a Baumgarten. Es preciso restituirle a la reflexividad una especificidad estético-crítica poniendo en relieve la idea de askesis de Baumgarten. Dijimos que la irreductibilidad aisthetica estriba en la fuerza natural de cierto sujeto que produce una obra, la cual imita aquella fuerza natural que le dio origen reteniéndola en sí. En tal sentido la poesía es autónoma. Para que la crítica no sea mera crítica simbólico-intelectual, sino realmente experiencia, Baumgarten ya había separado mathesis como práctica intelectual de askesis como práctica corporal. La fuerza natural es ejercitada no en el orden conceptual sino somático, lo cual se enmarca en un sistema de disciplinamiento de los cuerpos. Al respecto, Menke retoma la idea de Foucault en Vigilar y Castigar donde los sistemas de disciplinamiento son sistemas de subjetivación cuyo poder disciplinario controla los cuerpos ejercitándolos no de modo represivo sino productivo (271). La diferencia que Menke propone entre subjetivación panóptica y subjetivación estética radica en la imposibilidad de disciplinar a un sujeto que ya en la consideración de Baumgarten era una fuerza que jamás será absorbida por el disciplinamiento:

\footnotetext{
Esta es la diferencia entre el sujeto estético y el poder disciplinario: el poder de la disciplina [...] presupone o bien utiliza la posibilidad de control y dominio de sí mismo; en cambio, la disciplina de la estética muestra -este es su punto de crítica a la modernidad- que [...] la condición de esta posibilidad [la fuerza] es al mismo tiempo la de su imposibilidad [de ser disciplinada], de la imposibilidad de su pureza estética (287).
}

Proponemos ahora cierto distanciamiento de Menke al sostener que, en última instancia, la diferencia esencial no radica en la mencionada imposibilidad, sino en una reflexividad cuya tesitura contrapanóptica nos vuelve a situar en el cuerpo como punto axial, esto es, una reflexividad como askesis contrapanóptica.

En la panópsis tradicional (Bentham, Foucault) se genera una instancia simbólica externa que, una vez introyectada en el orden de la conciencia y el imaginario, sirve como mecanismo de autocontrol y disciplinamiento. En el caso de la askesis baumgarteniana la instancia disciplinante que se genera no es ni externa ni puramente simbólica, más bien es producto sincrónico, coetáneo del mismo cuerpo. El 
baumgarteniano disciplinamiento askésico, a diferencia del panóptico, no contrapone dos vectores, orienta un solo vector, el de la sensibilidad; vector somático no vigilado desde un elemento heterónomo, sino por el mismo ejercicio autónomo del cuerpo. El nomos directriz es creado y configurado en su especificidad mediante un ejercicio homólogo que, por cierto, no es teleológico. La fuerza, no predeterminada a priori, es polimorfa. De allí la reivindicación del orden cuantitativo de la extensión que hace Baumgarten. El criterio de disciplinamiento es un placer/displacer que en sí mismo es somático y simbólico: sensaciones propias del mismo cuerpo y de un peculiar modo de pensar, el pensar en modo bello. El origen de todo este proceso es la fuerza desde, en y para el cuerpo, la cual desembocará en la formación del gusto como emergente sincrónico de la askesis contrapanóptica que opera a tientas mediante un ensayo-error de corte somático. Sin reglas a priori universales, el cuerpo inventa su propio criterio de autodisciplinamiento contrapanóptico, según grados de fuerza. Este no opera sobre una qualitas intensiva sino sobre un quantum extensivo. La cualidad de un poema radica en la cantidad de materiales que el ingenio combina y que progresivamente se agudiza en prácticas de ensayo-error.

El contrapanóptico autodisciplinamiento askésico baumgarteniano es una política y administración de la fuerza ya no restringida heterónomamente, es decir, no se encuentra basada en un supuesto sujeto metafísico de la conciencia que introyecta un elemento de vigilancia. No hay un alguien que incorpora ni un algo que incorporar. En este sentido, la reflexividad, de la obra de arte es correlativa a la reflexividad del cuerpo. A fortiori, esta reflexividad aparece en la idea de Baumgarten de distinción extensiva (Aesthetica $\$ \$ 38,98$ ), una distinción propiamente somática. Demos un breve rodeo desde el interlocutor de Baumgarten. Como sabemos, para Descartes claridad y distinción permanecen en el orden del pensamiento, no de la extensión, la claridad se refiere al modo en que se presenta una idea ante la conciencia y la distinción a sus singulares notas esenciales. Para Baumgarten, en cambio, la claridad está en el orden de la extensión sensible pero también allí hay distinción. El cuerpo distingue espontánea y perfectamente lo bello y lo feo. La distinción extensiva no es una operación mental sino una espontánea reacción del cuerpo, una reacción que no nos deja tiempo para pensar, una reacción automática. Ante algo repulsivo, feo, ante algo bello o sublime, nuestro cuerpo reaccionó antes de que nos diésemos tiempo para juzgar y pensar en términos conceptuales. Este juicio somático, no conceptual, es coetáneo a la sensación. La distinción extensiva es lo que llamamos reflexividad, pero, esta vez -y este es nuestro desplazamiento de Menke-, en su retorno al cuerpo. Reflexividad de la obra y reflexividad askésica son experiencias simultáneas. Desde allí podemos ver que la subjetivación estética, según esta reflexividad coetánea cuerpo-obra, es un mecanismo de disciplinamiento no predeterminado ya que no hay un punto xerox heterónomo teleológico: de no ser así, no podríamos explicar la dispersión fractal del gusto.

Si bien tanto la fuerza como la ironía no construyen y destruyen de modo excluyente, la reflexividad askésica acentuará el plano constructivo mientras que la 
reflexividad irónica el plano destructivo. En ambos casos, la crítica es propiamente crítica en la medida en que constituye una acción de y en el cuerpo. Podemos ahora, desde las ideas de ironía y fuerza askésica contrapanótica desarticular la tradicional unión entre modernidad y sujeto.

\section{Referencias}

Baumgarten, Alexander. Metaphysica. Halae Magdebvrgicae, Impensis Carol Herman Hemmerde 1779.

---. Aesthetica. Hamburgo: Meiner Verlag, 2007. Impreso.

Beiser, Frederick. German Idealism: The Struggle Against Subjectivism, 1781-1801. Massachusetts: Harvard University Press, 2000. Impreso.

---. The Romantic Imperative: The Concept of Early German Romanticism. Massachusetts: Harvard University Press, 2003. Impreso.

Benjamin, Walter. El concepto de crítica de arte en el romanticismo alemán. Madrid: Abada, 2007. Impreso.

Bentham, Jeremy. El panóptico. Buenos Aires: Quadrata, 2005. Impreso.

Bohrer, Karl. Die kritik der Romantik. Frankfurt: Suhrkamp Verlag, 1989. Impreso.

Burger, Christa y Peter Bürger. La desaparición del sujeto. Madrid: Akal, 2001. Impreso. Butler, Judith. El género en disputa. Buenos Aires: Paidós, 2007. Impreso.

Blanchot, Maurice. La conversación infinita. Madrid: Arena Libros, 2008. Impreso.

Bloom, Harold. "La desintegración de la forma". Destrucción y Crítica. México: Siglo XXI, 2003. 11-46. Impreso.

Cassirer, Ernst. Filosofía de la Ilustración. México: FCE, 2008. Impreso.

De Man, Paul. Alegorías de la lectura. Barcelona: Lumen, 1990. Impreso.

---. La ideología estética. Madrid: Cátedra, 1998. Impreso.

---. La retórica del romanticismo. Madrid: Akal, 2007. Impreso.

Eagleton, Terry. La estética como ideología. Madrid: Trotta, 2006. Impreso.

Foucault, Michel. Vigilar y Castigar. Buenos Aires: Siglo xxI, 2008. Impreso.

Galfione, María Verónica y Juárez, Esteban. "Debates estéticos postadornianos”. Modernidad estética y filosofía del arte I. Córdoba: Gráfica 29 de mayo, 2013. 12-24. Impreso.

Gasché, Rodolphe. "Foreword. Ideality in Fragmentation". Philosophical Fragments. F. Schlegel, Minneapolis: University of Minnesota Press, 1991. vii-xxxii. Impreso.

Hamann,J. G. "La metacrítica sobre el purismo de la razón pura”. ¿Qué es ilustración? vv.AA. Madrid: Tecnos, 1999. 36-44. Impreso.

Hernández Sánchez, Domingo. La ironía estética. Salamanca: Universidad de Salamanca, 2002. Impreso.

Leibniz, Gottfried. Discurso de Metafísica. Madrid: Alianza, 1982. Impreso.

Menke, Christoph. La soberanía del arte. Madrid: Visor, 1997. Impreso. 
---. La actualidad de la tragedia. Madrid: La Balsa de la Medusa, 2008. Impreso.

---. Estética y negatividad. México: FCE, 2011. Impreso.

Nancy, Jean-Luc y Philippe Lacoue-Labarthe. El absoluto literario. Buenos Aires: Eterna Cadencia, 2012. Impreso.

Sánchez Meca, Diego. Modernidad y romanticismo. Madrid: Tecnos, 2013. Impreso. Schlegel, Friedrich. Lucinde. Valencia: Natán, 1987. Impreso.

---. Poesía y filosofía. Madrid: Alianza, 1994. Impreso.

---. "Fragmentos de Athenäum". El absoluto literario. J. L. Nancy y P. Lacoue-Labarthe. Buenos Aires: Eterna Cadencia, 2012. 132-225. Impreso.

Vattimo, Gianni. El fin de la modernidad. México: Gedisa, 1986. Impreso.

---. Más allá del sujeto. Barcelona: Paidós, 1992. Impreso.

Vieweg, Klaus. "Ironía romántica como skepsis estética”. Estudios de Filosofía 25 (2002): 53-70. Impreso.

Recibido: 20 noviembre 2014 Aceptado: 24 mayo 2016 